\title{
Gastrointestinal Helminthic Challenges in Sheep and Goats in Afro-Asian Region: A Review
}

\author{
Dinesh. K. Sharma*, Souvik Paul and Kumaresan Gururaj \\ Animal Health Division, Central Institute For Research on Goats, Makhdoom, PO Farah, Mathura (UP), INDIA \\ *Corresponding author: DK Sharma; E-mail: lkofwb@yahoo.co.in
}

Received: 02 Sept., 2019

Revised: 09 Jan., 2020

Accepted: 15 Jan., 2020

\begin{abstract}
Sheep and goats, being hardy and prolific in their growth, play a crucial role in cultural and socioeconomic life of rural poor under privileged people in Afro-Asian countries by providing meat, milk, wool and hide to them. Gastrointestinal helminthic infections are worldwide problem in ruminants. They results considerable loss in them causing mortality and poor production. Various helminthes types like trematodes, cestodes and nematodes are prevalent in different climates and geographical regions depending on rearing systems, intermediate host's availability and management practices. Epidemiology of helminthic diseases, though variable at times, is determined by various factors like treatment, climate and poverty (socio-economic and traditional practices). The study oversees gastrointestinal helminthic challenges in goats and sheep faced in Afro-Asian region in last decade. Methodology involves exhaustive exercise of screening and massive literature hunt which included published research, both abstracts and full length papers on the subject in last 10 years in addition to authors own observations. The diseases like Fasciolosis, Dicrocoelosis, Amphistomosis in trematodes, Monieziosis, Avitellinosis in cestodes and Haemonchosis, Trichostronglylosis, Oesophagostomosis, Trichuriosis, Strongyloidosis in nematodes were still serious challenges in the region threatening the small ruminant production. Frequent reports on Marshallgia, Ostertagia, Nematodirus, Stilesia, Thysaniezia spp. from this region showed emerging threats. Infections like Camelostrongylus, Graphidiops, Parabronema and Skrjabinema spp. were scarcely distributed. The paper reviews scientific work and developments of last 10 years on occurrence, distribution and epidemiology of common gastrointestinal helminthic infections of sheep and goats in Afro-Asian region with future research prospective in light of newer scientific approaches.
\end{abstract}

Keywords: Helminthes, Sheep, Goats, Epidemiology, Research Gaps

Sheep and goats are important livestock species in AfroAsian region of the world where three-forth of their world population of resides. Both the species play an important role in this region in providing food security to large population of small and marginal farmers and poor landless peoples. Through production of meat, milk, skin and wool they contribute significantly to their subsistence, employment generation and poverty alleviation. Production of sheep and goats, however, suffers severely from various infectious diseases of bacterial, viral and parasitic nature along with other management problems. Gastrointestinal helminthes infections (Trematodes, Cestodes and Nematodes) in small ruminants, both in intensive and extensive management, are considered serious constraints in their production as they lead to serious economic losses through lowering production of their produces along with morbidity and mortality. Further, substantial economic losses are encountered by the farmers in sheep and goat production in the form of expenditure incurred to control the helminthic infections. Local environment and climatic conditions along with traditional management practices and prevalence of intermediate host, if involved, determine the occurrence and pathogenesis of helminthic infections. Study of epidemiology of helminthic infections is important because they have wide geographical distribution in different regions world over. Epidemiological study

How to cite this article: Sharma, D.K., Paul, S. and Gururaj, K. (2020). Gastrointestinal helminthic challenges in sheep and goats in Afro-Asian region: a review. J. Anim. Res., 10(1): 01-18. 
provides us an important tool to prevent and control of these diseases. However, epidemiology is likely to change as an effect of natural and manmade adversaries of various natures. Global or local changes like variation in environmental temperature, total rain fall and humidity, water resources, level of different types of pollutions, use of chemicals in agriculture, depleting feed and fodder in pastures along with large scale shift in agricultural and animal husbandry procedures are likely to influence the occurrence and severity of these infections as both primary and secondary hosts along with different parasitic stages outside are continuously under stress. Climate changes bring adaptability changes in parasites which may involve strain variation in phenology, within genotype or host switching. Such changes work as strokes, be positive or negative, for parasites survival. In the light of present scenario, the paper reviews gastrointestinal helminthic challenges of sheep and goats of last decade and suggests future research perspectives.

\section{TREMATODES INFECTIONS}

\section{Fasciola spp.}

Infection of Fasciola spp. remained quite common in sheep and goats during last decade. It has been reported from different parts of Afro-Asian region like India (Sutar et al., 2010; Lone et al., 2012; Khajuria et al., 2013), Pakistan (Farooq et al., 2012), China (Huang et al., 2004), Bangladesh (Rahman et al., 2014; Hossain et al., 2015), Iran (Ali et al., 2011; Khanjari et al., 2014), Thailand (Worasing et al., 2011), Ethiopia (Sissay et al., 2007; Dagnachew et al., 2011; Ibrahim et al., 2014; Gizachew et al., 2014), Tanzania (Mhoma et al., 2011), Zimbabwe (Zvinorova et al., 2016), Kenya (Musotsi et al., 2017). Fasciolosis is responsible for 3.28-4.8 percent of total liver condemnation in ruminants (Ali et al., 2011; Mhoma et al., 2011; Khoramiam et al., 2014). Fasciola hepatica and $F$. gigantica are the two common species affecting the small ruminants. It carries public health importance also and as per WHO (2006) estimates 2.4 million people were infected with Fasciola hepatica and a further 180 million were at risk of infection. Arbabi et al. (2018), from Iran, reported that Fasciola spp. infection caused financial losses of 7160 and 6098.4 USD magnitudes during 20132016 in sheep and goat respectively.
The incidences reported in various studies from different places were different. From Pakistan the reported incidence in Sheep was as high as 2.8 to 40 percent (Farooq et al., 2012) against 15.6-29.35 percent in India (Lone et al., 2012; Nagesh and Das, 2013; Nagesh and Das, 2015) and 14.29-46.67 percent in Bangladesh (Rahman et al., 2014; Hossain et al., 2015). The overall prevalence of fasciolosis in sheep and goats in Iran was described to 0.35-22.8 and 0.50-11.4 percent respectively (Ali et al., 2011; Khanjari et al., 2014). However, in sero -prevalence study from Turkey through in-house ELISA technique, Akca et al. (2014) described prevalence of Fasciola spp. infection as high as 93 percent in sheep.

Various reports from different parts of India on goats described fasciolosis 9.25 percent in Maharashtra (Sutar et al., 2010), 3.88-14.8 percent in Jammu and Kashmir (Khajuria et al., 2013). The prevalence of the disease was reported higher in sheep than goats (Dagnachew et al.,2011). In Africa fasciolosis incidence in Sheep and goats respectively ranged from 9-19.6 and 0.9-7.6 percent (Gizachew et al., 2014; Ibrahim et al., 2014) in Ethiopia and 37 and 36 percent in Kenya (Kenyari et al., 2009), 4.28.2 percent in Tanzania (Mhoma et al., 2011). Zvinorova et al. (2016) reported Fasciola spp. infection prevalence of 0.9-5.1 percent in goats from Zimbabwe.

Islam et al. (2016) from Bangladesh, described prevalence of Fasciolosis in goats as seasonal with highest prevalence recorded in rainy season. They found it more significantly occurring in female goats than males. Khanjari et al. (2014) reported that prevalence of Fasciola spp. was highest during spring $(8.3 \%)$ followed by autumn $(8.1 \%)$, winter $(5.9 \%)$ and summer (4.3\%). Bulbul et al. (2014) recorded highest Fasciola egg discharge (EPG) in winter followed by post- monsoon, pre-monsoon and monsoon season. Seasonality of Fasciola spp. infection has also been seen by other investigators also (Ali et al., 2011). Regional and annual variations in Fasciola spp. prevalence were considered associated with prevailing weather conditions (Relf et al., 2011). This is because the hatching of fluke eggs and multiplication of snail, the intermediate host, require proper high rainfall and temperature $\left(>10^{\circ} \mathrm{C}\right)$ (Taylor, 2012).

Fasciolosis remained significantly more prevalent in sheep than goats (Khanjari et al., 2014). Higher prevalence rate in sheep than goats was attributed to the grazing 
habits of sheep which graze plants from ground where metacercariae, the infective stages of Fasciola, were mostly found whereas goats nibbled from top branches and leaves away from ground (Theodoropaoulos, 2011; Khanjari et al., 2014). Talukder et al. (2010) described age and sex of the animals as important determinant factors in pathology of fasciolosis in goats. However, both sheep and goats were described as very susceptible to Fasciola hepatica and with no resistance to reinfection.

In general, pathology of the disease is similar in sheep and goats. In sheep common lesions of livers were variable degree of cholangitis, biliary obstruction, fibrosis, hyperplasia, hemorrhages, enlargement, fibrinous exudation and oedema (Khan et al., 2015). In goats, affected livers were enlarged with hemorrhagic spots, hepatic bile duct protruding and engorged (Islam et al., 2016). They described microscopic hepatic lesions as hemorrhagic migratory tracks marked with infiltration of numerous eosinophils and lymphocytes, fatty changes, atrophy, thickened bile duct with hyperplasia of epithelial lining (Talukder et al., 2010). Calcification of bile duct in chronic infection of Fasciola spp., as seen in cattle, was not featured in sheep and goats (Talukder et al., 2010; Islam et al., 2016).

The gravity of problem and economic losses due to fasciolosis in sheep and goats in Afro-Asian region can be realized by extrapolation of study conducted by Khoramian et al. (2016) who reported an economic loss of 23360 USD and 30240 USD in sheep and goats respectively in Iran.

\section{Dicrocoelium spp.}

Dicrocoelium spp. hepatic infection is responsible for direct losses in sheep and goats' production due to discard of parasitized livers and indirect losses through costs associated with anthelmintics treatments. It has been reported from Iran (Khanjari et al., 2014), India (Lone et al.,2012; Khajuria et al., 2013; Godara et al., 2014), Nepal (Karki et al., 2012), Malaysia (Tan et al., 2017), Ethiopia (Sissay et al., 2007) and Nigeria (Usman et al.,2016). However, being asymptomatic and masked by the presence of pathological effects of multiple parasitic infections in ruminants, dicrocoelosis remained little known and underestimated by researchers. Arbabi et al. (2018) reported losses of USD 10880 and 9079.2 respectively in sheep and goats resulted from dicrocoelosis during 2013-2016 in Iran, mainly due to condemnation of damaged liver.

The incidence of dicrocoeliosis in sheep and goats varied from 3.63-20.0 and 2.6-5.0 percent respectively ( Khajuria et al., 2013; Khanjari et al., 2014; Godara et al., 2014; Ezatpour et al., 2015; Tan et al., 2017). Nevertheless, there were reports of 32 percent prevalence in goats from India (Lone et al., 2012). Sheep was described more susceptible to D. dendriticum infection (Khanjari et al., 2014). However, higher infection infection rate was observed in older animals.

Ali et al. (2011) from Iran and Godara et al. (2014) from India described it to be seasonal and spring/winter season was found to have highest prevalence (Ezatpour et al., 2015). However, Khanjari et al. (2014) reported that $D$. dendriticum infection did not follow any seasonal pattern. The dicrocoelosis was described more frequently in lowlands or mountains pasture lands at high altitudes and it was considered that chalk or alkaline soils favors the development of the vector snails and ants (Rojo-Vazqiez et al., 2012; Arabi et al., 2011).Unlike Fasciola spp., the intermediate hosts, in case of Dicrocoelium spp. infection were field snails and did not require much moisture for propagation and remained widely distributed in pastures surviving months together (Taylor, 2012). Further environment and ecological aspects were considered the main important factors for Dicrocoelium life cycle between intermediate and definitive hosts (Arabi et al., 2011). Females showed a higher rate of dicrocoeliosis prevalence than males (Khanjari et al., 2014) probably due to sex as a determinant factor influencing prevalence of parasite specially during pregnancy and peri-parturient period due to stress and low immune status(Khan et al., 2010).

Jithendaran and Bhat (1996) reported livers in infected sheep and goats as swollen with thickened bile ducts, whitish spots on the surface, marked scarring and cirrhosis, with a large number of worms inside the bile ducts and gall bladder. Similarly, Arabi et al. (2011) from Iran reported liver distension along with severe fibrosis and obstruction of bile duct. They found a direct correlation between worm burden and lesion scores in infected animals. In general the disease has been reported far often from hilly pastures.

Though rarely, D. dendriticum, the lancet fluke, was reported carrying zoonotic importance. Samaila et 
al. (2009) described its infection in a 7 year old boy with clinical symptoms of jaundice and fever. Human infection could have been due to accidental ingestion of intermediate hosts, primary or secondary or through raw meat consumption. World health organization in 2007 included $D$. dendriticum on its list of organisms to target with its Food borne Diseases Epidemiology Reference Group (WHO, 2007).

\section{Eurytrema spp.}

In last decade the information about the subject lacked as literature on this parasite remained scanty except a few reports from Eastern Asia in sheep and goats (Sangvaranond et al., 2010; Jittapalapong et al., 2012; Xu et al., 2013). Owhoeli et al. (2014) from Nigeria reported Eurytrema spp. infection in goats through a slaughter house study while Sangvaranond et al. (2010) and Jittalapong et al. (2012) described it from Thailand in meat goats raised in private farms through faecal examination (0.84-1.3\%). Chang et al. (2016) characterized the complete mitochondrial genome from E. pancreaticum and established its close relation with Dicrocoelium chinensis and other members of Dicrocoelidae. Schwertz et al. (2015) has described Eurytrematosis, an emerging and neglected disease in recent time in Brazil and suspected human infection in the light of previous reports. There were two species main species, E. pancreaticum and E. coelomaticum, reported from sheep and goats, however, the first one was more frequently recorded throughout.

\section{Amphistomes}

Swarnkar and Singh (2012) have described the amphistomes infection one of the most economically important infections requiring particular attention in worm control programme. The condition is very common in small ruminants and has wide distribution. The disease has been reported from Ethiopia (Sissay et al., 2007; Dagnachew et al., 2011), Pakistan (Farooq et al., 2012), India (Swarnkar and Singh 2012; Kandasamy et al., 2013; Brahma et al., 2015), Bangladesh (Hossain et al., 2015), Thailand (Sangvaranond et al., 2010), Turkey (Ozdal et al., 2010), Malaysia (Tan et al., 2017). Choudhary et al. (2010) described paramphistomosis as a neglected trematodes disease of ruminants and a significant cause of economic losses.
The incidence reported in different studies in India ranged from as low as 1.3 to 23.55 percent in sheep (Swarnkar and Singh, 2012; Lone et al., 2012; Kandasamy et al., 2013; Nagesh and Das, 2013; Maitra et al., 2014) and as high as 18.26 to 91 percent in Goats (Lone et al., 2012; Singh et al., 2015). In African continent, the incidence in sheep was 3.1-19.6 percent in Ethiopia (Gizachew et al., 2014; Ibrahim et al., 2014), 9.38 percent in Egypt (Sultan et al., 2016), 4.43 percent in Turkey (Ozdal et al., 2010). In goats, Mhoma et al. (2011) from Tanzania and Zvinorova et al.(2016) from Zimbabwe reported prevalence as 7.3 and $0.6-24$ percent respectively.

Swarnkar and Singh (2012) reported peak prevalence in June-August in Rajasthan, India and described it as summer enteritis syndrome. In goats, highest prevalence was reported in monsoon and lowest in winter (Choubisa et al., 2010; Singh et al., 2015) and associated it with probable availability of intermediate host, the snails. Maitra et al. (2014) reported highest mean EPG during monsoon and post monsoon in goats and sheep. On the other hand, Yadav et al., (2010) described more cases in summer than rainy season. The highest incidence in sheep in Turkey was reported during autumn followed by summer (Ozdal et al., 2010), however, it was reverse in Iran (Tehrani et al., 2015). Maitra et al. (2014) described the difference in species/season/monthly prevalence due to the differences in the agro climatic conditions, availability or abundance of intermediate hosts, animal husbandry/ management practices, length of survey period, sample size and method of sampling. There was no evidence of auto expulsion of amphistomes from host body (Maitra et al., 2014).

Kenyari et al. (2009) from Kenya and Ibrahim et al. (2014) from Ethiopia reported prevalence of Paramiphistomum spp. significantly low in animals with good body conditions. Ibrahim et al. (2014) also described significantly higher prevalence in young and female sheep and goats.

There were several species of amphistomes affecting sheep and goats in particular. The common prevalent amphistomes were described as Paramphistomum, Cotylophoron, Calicophoron, Gastrothylax species. Farooq et al. (2012) from Pakistan reported Cotylophoron spp. infection in sheep. Tehrani et al. (2015) described three species from sheep carcass as $P$. cervi, Cotylophoron cotylophorum and G. crumenifer in Iran. Tan et al., (2017) from Malaysia described Paramphistomum spp. in goats. 
Bulinus species of snails are found to play important role in amphistomes life cycle. Common snails described as intermediate hosts were Bulinus syngenes, B. alluaudi (Kenya), B. truncates (Iran, Egypt), Planorbis planorbis (Bulgaria), Indoplanorbis exustus (India).

Ozdal et al. (2010) observed that pathogenic effect of paramphistomosis was dependent on the number of parasites in animals and described the adult fluke infections as harmless except chronic ulcerative rumenitis along with ruminal papillary atrophy when flukes' number was large. Maitra et al. (2014) reported as high as 80-90 percent mortality rate due to immature paramphistomosis in domestic ruminants. Tehrani et al. (2015), among 2421 sheep tissue specimens in paramphistomosis, recorded major gross lesions as hyperemia, haemorrhage ulcers and nodular protrusions of different sizes and shapes in intestines along with dilatation and superficial destruction of intestinal glands and infiltration of erythrocytes and inflammatory cells and fibrinous membrane around them. Melaku and Addis, (2012) from Ethiopia quoted mature amphistomes infection with rumenitis, irregular rumination, un-thriftiness, lower feed conversion rate and loss of body conditions resulting in considerable economic loss. Clinical paramphistomosis in small ruminants is manifested by anorexia, profuse fetid diarrhea, drop in plasma protein concentration and anemia. Balakrishnan et al. (2014) described clinical signs of amphistomosis in native Indian goats as profuse fetid diarrhea, sub mandible oedema, anaemia, anorexia, weakness, dull and depression.

Diagnosis of amphistomosis conventionally depended on clinical signs, immature parasites in diarrheic fluid and amphistomes eggs in the faeces. However being marked seasonality in egg production and pathogenic effect being limited to immature stage of amphistomes, the diagnosis of based on conventional methods was found difficult in routine investigation (Saifullah et al. 2011). Attempts on immunodiagnostics have been made (Saifullah et al., 2011) but still a reliable diagnostic test remained a far dream to achieve. Saifullah et al. (2011) detected a $33 \mathrm{kDa}$ protein excreted/secreted by Gastrothylax crumenifer as immunodominant to be used as antigen in its diagnosis.

\section{Schistosomes}

In last decade, Schistosoma spp. infection was reported from Bangladesh (Rabbi et al., 2011; Sangma et al., 2012); Nepal (Karki et al., 2012); Nigeria (Amadi et al., 2012; Owhoeli et al., 2013; Usman et al., 2016), Ghana (Futagbi et al., 2015), Ethiopia (Kerie and Seyoum, 2016). The prevalence of infection ranged between 3.2-44.4 percent in goats (Rabbi et al., 2011; Karki et al., 2012; Futagbi et al., 2015). Amadi et al. (2012) and Owhoeli et al. (2013) from Nigeria reported a prevalence of 6.421.1 percent in goats through faecal examination. Sangma et al., (2012) and Kerie and Seyoum, (2016) reported prevalence of infection in sheep as 3.7 and 2.3 percent in Bangladesh and Ethiopia respectively. Swarankar et al. (2019) reported prevalence of schistosome as 0.19 percent in Rajasthan sheep. Prevalent species in sheep and goats were S. haematobium (Futagbi et al., 2015), S. bovis (Kerie and Seyoum, 2016) and S. indicum (Sangma et al., 2012, Swarnkar et al. (2019). Agrawal (2012) described $S$. indicum, S. spindale and S. incognitum in Indian goats occurring both as monospecies or sympatric infections. However, he reported absence of sympatric infection of $S$. indicum and $S$. incognitum suggesting a strong heterologous immunity between the two species. Agrawal, (2012) considered $S$. indicum responsible for outbreaks and considerable mortality in sheep in Indian states. He described $S$. spindale as species widely distributed in more countries than $S$. indicum and dominating species in goats. Kerie and Seyoum, (2016) reported no association of host age or gender to schistosome infection in sheep.

\section{Gaps in Trematodes Research}

Epidemiology of infections provides an important tool to control the diseases. However, there exists a big knowledge gap in relation to epidemiology of trematodes infection in snail, the intermediate host. Study of snail species spectrum, interaction between snail and parasites, snail habitats and behavior with respect to meteorological changes along with population dynamics is required to fill the knowledge gap and to control the disease. Further in developing countries, Amphistomosis could not get much attention for diagnosis compared to other trematode infections like Fasciolosis and Schistosomosis because the later were considered more important being more of pervasive and of zoonotic nature. There is a lot of scope to study the dynamics of the intermediate stages of these trematodes in the cold-blooded host like snail. The major area, which needs to be addressed, is to understand the 
immune-genomics of the snail with the recent technologies of gene-editing tools like CRISPR. This untouched domain could decipher the molecular pathogenesis and signatures that aids in the development of parasite in the definitive host. Soon these techniques could address the diagnostic and vaccine targeting issues for disease control.

Application of modern techniques like PCR, recombinant technique, transcriptomics in schistosomes study are to be used to unfold the epidemiology and immunity part. Further, the study of epidemiology of infections in snail, the intermediate host, along with the proteomics is necessary to impound the problem in livestock and human as well.

\section{ANOPLOCEPHALID CESTODES}

\section{Moniezia spp.}

Among cestodes infections of small ruminants, Moniezia spp. infection is most common and world widely distributed. It has been reported from Bangladesh (Nath et al., 2011; Rahman et al., 2014; Hossain et al., 2015 ), India (Swarnkar and Singh, 2012; Lone et al., 2012; Nagesh and Das, 2013; Brahma et al., 2015; Verma et al., 2017), Korea (Gebeyehu et al., 2013), Sri Lanka (Kandasami et al., 2013), Syria (Almalaik et al., 2008), Nigeria (Owhoeli et al., 2014), Thailand (Worasing et al., 2011), Malaysia (Tan et al., 2017), Ethiopia (Dagnachew et al., 2011; Gizachew et al., 2015).

The prevalence of moniezial infection in sheep as described by various workers ranged from 0.2 to 30.4 percent (Almalaik et al., 2008; Kenyari et al., 2009; Swarnkar and Singh 2012; Kandasami et al., 2013; Gizachew et al 2015; Ibrahim et al., 2014; Nagesh and Das 2013). In goats, prevalence range described was 0.1- 40.34 percent (Almalaik et al., 2008; Kenyari et al., 2009; Worasing et al., 2011; Shaikh et al., 2011; Nath et al., 2011; Rahman et al., 2014; Ibrahim et al., 2014; Hossain et al., 2015; Brahma et al., 2015; Tan et al., 2017; Verma et al., 2017; Hassan et al., 2019). Sissay et al. (2008) reported Moniezia prevalence as high as 61 and 53 percent in Sheep and Goats respectively from Ethiopia. Dagnachew et al. (2011) from Ethiopia, and Attindehou and Salifou, (2012) from Benin reported that prevalence of Moniezia infection in sheep was significantly higher than in goats. Kumsa et al. (2011) from Ethiopia also reported sheep being more vulnerable to infection. There were two species of Moniezia in small ruminants i.e. Moniezia expansa and M. benedeni, the first being more common (Kandasami et al., 2013; Aragaw and Gebreeegziaber, 2014) but Sangavaranond et al., (2010) found M. benedeni more prevalent species in goat in Thailand. Nguyen et al. (2012) based on PCR study in Vietnam described $M$. expansa as dominant spp. in sheep and goats whereas $M$. benedeni more common in cattle.

Nagesh and Das (2013) from India reported Moniezia spp. more prevalent in sheep in winter season. Kandasami et al. (2013) found higher prevalence rate after rainy season. Attindehou and Salifou, (2012) from Benin described the infection prevalent in all season nevertheless high rates in rainy seasons (beyond 50\%). Nath et al. (2011) attributed the seasonal variation in incidence of Moniezia infection to active period of forage mites, the intermediate host for parasite. They reported the infection being more common in kids during one year of age than the older animals. Abdel-Megeed et al. (2014) from Egypt described the sero-diagnostic value of partially purified antigen of Moniezia expansa and reported infection prevalence of $69.7 \%$ and $74.4 \%$ in sheep and goats respectively. Moniezia spp. infection has also been associated with poor body conditions and age in goats.

Infection of Moniezia spp. in animals was reported to cause severe pathogenic effects viz. disturbance of gastrointestinal motility, secretion, diarrhea and anemia along with reduced slaughter yield, increased water content and reduction in protein and fat.

\section{Stilesia spp.}

Among anoplocephalids, Stilesia spp. infection is quite important and frequently observed in small ruminants. There had been several reports of this infection in small ruminants from Asia (Siddiqua, 2010; Mir et al., 2013; Sankar et al., 2016) and Africa (Sissay et al., 2008; Ndom et al., 2016). In India, a prevalence rate described in goats varied between 2.5-36.6 percent (Siddiqua, 2010; Mir et al., 2013; Sankar et al., 2016). Siddiqua, (2010) recorded a prevalence of 2.91 and 2.5 percent in sheep and goats respectively and described species as $S$. vitatta. In a 7 year slaughter house study, Sankar et al. (2016) described Stilesia as one of the neglected and economically important tropical parasites. Sissay et al., (2008) and Ndom et al. 
(2016) reported Stilesia spp. infection in small ruminants from Africa. The prevalence of infection was as high as 39 percent in sheep and 36 percent in goats (Sissay et al., 2008). Sissay et al. (2008) described both Stilesia globipunctata and $S$. hepatica species affecting sheep and goats and Stilesia hepatica being more prevalent than $S$. globipunctata. Shankar et al. (2016) dsecribed sex and age as important factors affecting the incidence and reported male and age (6-12 M) being more susceptible and infection reaching its peak during rainy season. The infection is insect born and Scheloribates indica and Erythreus spp. were intermediate hosts for S. globipunctata.

\section{Avitellina spp.}

Avitellina spp. infection was reported in Asia in last decade from India (Siddiqua 2010, Lone et al., 2012), Iran (Naem and Gorgani, 2013,). Siddiqua, (2010) reported Avitellina spp. infection prevalence of 8.75 percent in sheep from Kanpur Dehat, India. Lone et al. (2012) reported prevalence of Avitellina spp. infection in slaughtered sheep and goats respectively as 17.75 and 24.25 percent from J \& K state of India. Naem and Gorgani, (2013) from Iran reported Avitellina spp. prevalence in sheep as high as 20 percent. There had been several reports of Avitellina spp. infection in sheep and goats from Africa during last decade (Sissay et al., 2008; Ndom et al., 2016; Elkhatam and Khalafalla, 2016). Sissay et al., 2008 from Ethiopia described Avitellina spp. in sheep and goats (20-39.5\%). Ndom et al. (2016) from Senegal reported prevalence of Avitellina sp. as high as 38.7 percent in sheep. Elkhatam and Khalafalla, (2016) reported 4.0 percent prevalence of Avitellina infection in goat from Egypt in slaughter house study. They described the species as A. centripunctata. However, Taylor et al. (2016) described 3 more species of Avitellina as A. goughi, A. chalmersi and A. tatia sheep and goats.

\section{Thysaniezia spp.}

The anoplocephalide cestode, Thysaniezia infection in sheep and goats was reported by Solsby et al. (1987) from UK, USSR, Africa and America. During last one decade, it has been reported from India, Senegal and Egypt (Lone et al., 2012; Ndom et al., 2016; Bashtar et al., 2011). Lone et al. (2012) described Thysaniezia spp infection in sheep and goats (10.15 \& $17.85 \%)$ in J \& K state of India.
Ndom et al. (2016) from Senegal reported prevalence of Thysaniezia spp. sheep and goats as 0.4 and 2.1 percent respectively. Bashtar et al. (2011) reported this infection in sheep from Egypt with prevalence of 2.7 percent.

\section{Gaps in Cestodes Research}

The economic importance of infection of anoplocephalid cestodes in small ruminants is not well understood and it could not seek the required attention in past. However, their rampant and widely distributed occurrence in them along with pathogenic effects in severe cases emphasizes a well designed experimental study to explore the economic implications of these infections which cannot be ruled out and are likely to happen both directly or indirectly. A wholesome analysis of the pattern recognition receptor genes and their expression in response to anoplocephalids cutting across their hosts could unravel certain common factors supporting the development of these parasites. With the advent of the current developments in the molecular biology and next generation sequencing platforms, there is a possibility to delve in to every other important putative molecule that is involved in the development of the disease. Further, the proteomic study in area may be helpful to demonstrate the common candidate protein, if any, having vaccine potential.

\section{NEMATODE INFECTIONS}

\section{Haemonchus spp.}

Haemonchosis in sheep and goat is a worldwide problem. Haemonchus spp. infection has been described as the most common and economically important strongyle nematode infection in sheep and goats (Almalaik et al., 2008; Sharma et al., 2009; Swarnkar and Singh; 2012; Asaolu et al., 2012; Farooq et al., 2012; Singh et al., 2013; Okoye et al., 2013; Kandasami et al., 2013; Brahma et al., 2015; Singh et al., 2015). In last 10 years, Haemonchus spp. infection has been reported from Gambia (Asaolu et al., 2012), Srilanka (Kandasami et al., 2013), Sudan (Almalaik et al., 2008), India (Sharma et al 2009; Sutar et al., 2010; Mandal et al., 2011; Swarankar and Singh 2012; Singh et al., 2013; Singh et al., 2015; Brahma e al., 2015; Bihaqi et al., 2017), Nepal (Karki et al., 2012), Iran (Naem and Gorgani, 2011), Bangladesh (Hossain et al., 
2015), Iraq (Mohammedameen, 2016), Nigeria (Okoye et al., 2013; Owhoeli et al., 2014; Soloman-Wisdom et al., 2014; Odeniran, et al., 2016), Ethiopia (Sissay et al., 2007), Cameroon (Ntonifer et al., 2013), Ghana (Blackie 2014; Futagbi 2015).

Prevalence of Haemonchus infection described time to time varied in different places and species. In goats, 26.0 percent from Sudan (Almalaik et al., 2008), 24.25-70.0 percent from India (Sharma et al., 2009; Sutar et al., 2010; Singh et al.,2013), 61.5-69.5 percent from Nigeria (Okoe et al., 2013), 67.5 percent from Ethiopia (Badaso and Addis, 2015), 10-14.5 percent in Nepal (Karkiet al., 2012), 62.8 percent in Ghana (Futagbi et al., 2015). Interestingly, Bandhyopadhyaya et al. (2010) reported Haemonchus contortus prevalence in 76.8 percent cases from reticulum rather than in abomasums. Prevalence in sheep reported was 53.4 percent from Sudan (Almalaik et al., 2008), 47.0 percent in India (Singh et al., 2004), 75-81.3 percent in Sri Lanka (Kandasami et al., 2013) and 56.6 percent from Ethiopia (Badaso and Addis, 2015). Prevalence rates in two species have been reported to be significantly different (Badaso and Addis, 2015). Futagbi et al. (2015) described higher prevalence of Haemonchus infection in imported than in local goats in Ghana.

Qamar et al., (2009) from Pakistan reported the highest prevalence of Haemonchus infection during summer and more in younger animals (below 9 month) compared to older animals. The high humidity, in microclimate of faeces and the herbage, being essential for larval development and survival, was described to be the cause of frequent and severe outbreaks of GI nematode infection in rainfall season. Sissay et al. (2007) from a study in sheep in Ethiopia reported high levels of gastrointestinal nematode infections occurring during rainy seasons and $H$. contortus being most predominantly occurring GIN. Physiological states like pregnancy, age and lactation in animals were found to affect the faecal egg counts in $H$. contortus infected animals and thus the susceptibility their of (Agrawal et al., 2010). Raza et al. (2014) attributed the higher prevalence of Haemonchus infection to short generation interval of this nematode along with high fecundity. Chiejina et al. (2015) described West African Dwarf goat as haemonchotolerant. There existed resistance within and between the breeds of sheep and goats against Haemonchus spp. (Babar et al., 2015) which was regulated by immunological response against the infection. However, the mechanism remained still as an enigma.

Symptoms of acute haemonchosis were described as dark coloured faeces with blood and sudden death of affected animals (Kandasami et al., 2013). Kandasami et al., (2013) described the Haemonchus spp. infection leading immunosuppression which predisposes the animals towards secondary infections. Blackie (2014) described $H$. contortus blood sucking worms resulting anaemia and weight loss in areas permanently warm and humid or having prolonged warm rainy season.

\section{Trichostrongylus spp.}

Trichostrongylosis is an important roundworm disease of small ruminants. It is widely distributed. Trichostrongylus spp. infection, in last one decade, was reported from Pakistan (Farooq et al., 2012; Raza et al., 2014), Sudan (Almanaik et al., 2008), Ethiopia (Sissay et al., 2007; Dagnachew et al., 2011), India (Swarnkar and Singh, 2012; Singh et al., 2013; Brahma et al., 2015), Nigeria (Okoye et al., 2013), Botswana (Sharma and Busang, 2013), Cameroon (Ntonifor et al., 2013), Ghana (Blackie 2014).

The prevalence of Trichostrongylus spp. infection was varied. It ranged in goats from 5.68 to 28.33 percent in India (Lone et al., 2012; Brahma et al., 2015), 13.8-21.1 percent in Pakistan (Farooq et al., 2012) 24.4 percent in Sudan (Almalaik et al., 2008), 23.2-77.5 percent in Ethiopia (Aragaw and Gebreegziabher, 2014; Ibrahim et al., 2014) 51.5 percent in Bangladesh. In sheep the prevalence varied 14.7 to 83.6 (Almalaik et al., 2008; Aragaw and Gebreegziabher, 2014; Swarnkar and Singh, 2012; Ntonifer et al., 2013; Lone et al., 2012; Farooq et al., 2012; Ibrahim et al., 2014). Trichostrongylus genus has been reported among the commonest of the GIT nematode infections in Ethiopia and Bangladesh along with Haemonchus, Nematodirus and Oesophagostomum (Sissay et al., 2007; Blackie, 2014). Farooq et al. (2012) described it as the $2^{\text {nd }}$ most important parasites from Pakistan. Ntonifor et al. (2013) reported that tethered animals had highest infection rates than free range grazer both in sheep and goats. The infection was found more frequent in animals with poor body conditions (Kenyari et al., 2009; Ibrahim et al., 2014). Raza et al. (2014) from Pakistan reported three species prevalent in sheep and 
Goats as Trichostrongylus colubriformis, T. axei and $T$. ovis. Blackie, (2014) reported the presence of two species as T. colubriformis and T. axei in Ghana.

Trichostrogylus spp. infection has been considered to thrive well in cool season and at times when mean monthly temperature ranged between 2.8 to $18.3{ }^{\circ} \mathrm{C}$. However, there are reports which suggest non conducive effects of cool season on Trichostrongylus spp. (Farooq et al., 2012).

\section{Ostertagia spp. (Teladorsagia)}

This is known as brown stomach worm of ruminant. The nematode has been reported from sheep in Egypt (Khalafalla et al., 2011; 1.2 percent) Pakistan (Raza et al., 2014, 4.2 percent) India (Khajuria et al., 2013) Iran (Naem and Gorgani, 2013; 38 percent) Ghana (Blackie, 2014). Asrani et al., (2011) reported Teladorsagia infection in migratory Gaddi sheep and goats from Himachal state in India and described lesions caused in abomasums as multiple tiny raised oedematous areas with petichae. Karki et al. (2012) from Nepal reported Ostertagia spp. infection in goats with a prevalence of 16.12 percent in summer. Raza et al. (2014) also reported its 2.4 percent prevalence in goats and described two spp. as Ostertagia (Teladorsagia) circumcincta and O. ostertagi. Blackie, (2014) described the species as Ostertagia marshalli.

Ostertagia (Teladorsagia) has been considered a major economic health hazard in sheep and goats in cool and moist climates and specially in Europe. Infection often referred more threatening, clinical and economic hazard when occurred concurrently with Trichostrongylus spp.

\section{Nimatodirus}

In last decade Nimatodirus spp. infection has been reported from Pakistan (Raza et al., 2014), India (Lone et al., 2012; Bihaqi et al., 2017; Tramboo et al., 2017), Iran (Naem and Gorgani, 2013), Iraq (Nasrullah et al., 2014; Mohammedameen, 2016), Egypt (Sultan et al., 2016), Ghana (Blackie, 2014).

Raza et al. (2014) reported the prevalence of Nimatodirus $\mathrm{sp}$. in goats $(1.4 \%)$ and sheep $(0.8 \%)$ from Pakistan. Sultan et al. (2016) described prevalence of Nimatodirus as 0.45 percent from Egypt on the basis faecal egg examination. Lone et al. (2012) reported Nimatodirus infection in slaughtered goats and sheep from J \& K state of India. They reported a prevalence of 32.60 and 27.40 percent in goats and sheep respectively. Bihaqi et al., 2017 and Tramboo et al. (2017) reported relative prevalence in sheep and goats respectively as 68.3 and 55.75 percent. Naem and Gorgani, (2013) and Mohammedameen, (2016) reported Nimatodirus infection prevalence in sheep as 14 and 16 percent from Iran and Iraq respectively. Nasrullah et al. (2014), from Iraq, reported Nimatodirus spathiger infection as major problem in goats with relative prevalence of 38.7 percent, the highest among gastrointestinal parasitic infections. Blackie, (2014) reported Nimatodirus filicollis presence in Ghana in sheep.

\section{Chabertia spp.}

This worm is also known as large mouth bowel worm and its infection is more rampant in temperate climate. However, it has often been reported from tropical region also. The prevalence of Chabertia described by different worker in sheep and goats was varied. In sheep, the reported prevalence was 4.2-17.4 percent from Ethiopia (Ibrahim et al., 2014), 0.6 percent from Egypt (Khalafalla et al., 2011), 24.0 percent from India (Lone et al., 2012), 2.0 percent from Iran (Naem and Gorgani, 2013), 1.25 percent from Iraq (Mohammedameen, 2016). However, the prevalence in goats ranged between $8.2-25$ percent (Amadi et al., 2012; Ibrahim et al., 2014; Nasrullah et al., 2014; Owhoeli et al., 2014; Bihaqi et al., 2017). In India, there were reports from Jammu and Kashmir regions describing the prevalence (Lone et al., 2012; Mir et al., 2013; Bihaqi et al., 2017; Tramboo et al., 2017). Lone et al. (2012) and Mir et al., (2013) reported Chabertia infection from sheep and goats (4.57-28.0 percent). Karki et al. (2012) reported prevalence of Chabertia in goats from Nepal as high as 33.7 percent. Raja et al. (2014) from Pakistan reported prevalence in 0.4 percent in sheep and 0.6 percent in goats. Ibrahim et al. (2014) reported significantly higher prevalence of Chabertia infection more in young than adult small ruminants. Blackie, (2014) reported its presence in sheep and goats from Ghana and considered it a pathogen in these species in winter rainfall areas.

\section{Oesophagostomum spp.}

The infection of Oesophagostomum spp. in sheep and 
goats have been reported from Bangladesh (Nath et al., 2011), Sudan (Almalaik et al., 2008), India (Swarnkar and Singh, 2012; Singh et al., 2013; Singh et al., 2015; Brahma et al., 2015), Ethiopia (Sissay et al., 2007; Asaolu et al 2012; Ibrahim et al., 2014), Ghana (Blackie, 2014), Nepal (Karki et al., 2012), Pakistan (Raza et al., 2014)

The prevalence of infection of Oesophagostomum from different parts ranged from as low as 2.2 percent to as high as 62.7 percent in sheep (Almalaik et al., 2008; Lone et al., 2012; Swarnkar and Singh, 2012) and 9.9 percent to 92 percent in goats (Almalaik et al., 2008; Nath et al., 2011; Karki et al., 2012; Brahma et al., 2015). Asaolu et al., (2012) described Oesophagostomum spp. as commonest worm of large intestine. Brahma et al., (2015) from West Bengal, India reported it the predominant infection in goats after Haemonchus sp. As concluded through coproculture examination. Bandhyopadhyay et al., (2010) described its two spp. infecting goats in India as O. columbianum and O. venulosum. Raza et al., (2014) described two spp. of this nematode in sheep and goats as $O$. columbianum and O. radiatum using keys given by MAFF, (1979).

Nath et al. (2011) reported highest occurrence of Oesophagostomum spp. in winter (100\%) from Bangladesh on examination of viscera. Almalaik et al., (2008) from Sudan reported least during dry season which increase gradually in rainy season. They observed positive correlation between worm burden and climatic factors like rainfall and humidity. Swarnkar and Singh, (2012), however, described highest Oesophagostomum spp. larvae occurrence in sheep faecal culture in February in stationary and in March in migratory flocks.

Nath et al. (2011) reported hard, raised, slightly yellowish to green colored nodules in large intestine of goats in Oesophagostomum spp. infection. Blackie (2014) from Ghana described that heavy burden of worms in small ruminants cause nodular colitis i.e. pimply gut which results in diarrhea and loss of condition. Jas et al., (2010) through an experimental study in Black Bengal goats reported significant decrease in haemoglobin, packed cell volume, total erythrocytes and leukocytes counts in experimental $O$. columbianum infection. They also described hyperglobulin aemia and hypoprotein aemia in infected goats along with significant decrease in serum iron specially on 70 DPI.

\section{Cooperia sp.}

In last decade prevalence of Cooperia spp. infection in small ruminants has been reported from Pakistan (Raza et al., 2014), Iran (Naem and Gorgani, 2013), Nigeria (Amadi, et. al., 2012), Ghana (Blackie, 2014), Botswana (Sharma and Busang, 2013). Amadi et al., (2012) reported its prevalence in African dwarf goats from Nigeria as 1.8 percent. Raza et al., (2014) described Cooperia infection in sheep from Pakistan and reported prevalence as high as 0.2 percent. Almalaik et al. (2008) from Sudan reported its prevalence as 3.1 and 0.1 percent respectively in sheep and goats post-mortem study. They described the species as Cooperia pectinata.

\section{Marshallagia marshalli}

In last decade the infection of Marshallagia marshalli was recorded from Algeria (Meradi et al., 2011), Iran (Naem and Gorgani, 2011; Moradpour et al., 2014) and Iraq (Al-Bayati and Arsalan, 2009; Nasrullah et al., 2014; Mohammedameen, 2016).

Meradi et al. (2011) reported prevalence of this nematode parasite in small ruminants ranging 21 to 81 percent in Algeria and established significant linear regression between prevalence of Marshallagia marshalli and rainfall. They reported association of low rainfall to higher $M$ marshalli prevalence. Naem and Gorgani, (2011) from Iran reported the parasite prevalence as high as 38 percent in sheep from slaughter house. There had been several reports from Iraq describing the infection in sheep and goats (Al-Bayati and Arsalan, 2009; Nasrullah et al., 2014; Mohammedameen, 2016). Al-Bayati and Arsalan, (2009) reported Marshallagia marshalli highest among prevalent parasitic infection $(62.9 \%)$ in Iraq (Mohammedameen, 2016). Nasrullah et al. (2014) reported the 33 percent relative prevalence of $M$. marshalli, the second largest after Nimatodirus spathiger, among gastrointestinal parasite infections in Sulaimani provice of Iraq. Moradpour et al., (2013) described pathophysiological changes in experimental M. marshalli infection in lambs as reduced acidity of abomasal contents, increased abomasal $\mathrm{pH}$ and increased serum pepsinogen concentrations with histological change as mucosal cell hyperplasia, loss of parietal cells and inflammatory cells infiltration. 


\section{Hookworms}

\section{Bunostomum spp.}

Bunostomum spp. infection in sheep and goats is common in Afro-asian region (Ibrahim et al., 2014; Karki et al., 2012; Amadi et al., 2012; Raza et al., 2014; Aragaw and Gebreegziabher, 2014; Brahma et al., 2015; Sangma et al., 2012; Naem and Gorgani, 2013). Prevalence of Bunostomum sp. (Hookworm) infection varied from 2.0-77.5 percent in sheep (Naem and Gorgani, 2013; Ibrahim et al., 2014; Aragaw and Gebreegziabher, 2014; Mohammedameen, 2016) to 3.2-38 percent in goats (Karki et al., 2012; Ibrahim et al., 2014; Aragaw and Gebreegziabher, 2014; Nasrullah et al., 2014). Amadi et al. (2012) from Nigeria reported Bunostomum spp. infection in African dwarf goats as high as 12.6 percent based on faecal examination. In India Bunostomum sp infection in sheep and goats has been reported from different places (Bandhyopadhyay et al., 2010; Khajuria et al., 2013) with varying prevalence. Raja et al., (2014) from Pakistan reported prevalence in 1.4 percent in sheep and goats. Sangma et al. (2012) reported its prevalence as 19 percent in sheep from Bangladesh.

Another hookworm, Gaigeria pachyscelis has also been described in sheep and goat during last decade (Almalaik et al., 2008; Asrani et al., 2011; Blackie, 2014). Almalaik et al. (2008) reported its prevalence (1percent) in Goats in Sudan. Asrani et al. (2011) reported Gaigeria pachyscelis infection in duodenum, jejunum and ileum in migratory sheep and goats' flock from Himachal state of India in mixed parasites outbreak. Bandhyopadhyay et al. (2010) reported its infection in goats from Shillong, Meghalaya.

\section{Camelostrongylus spp.}

It is nematode parasite of camel's abomasum. However, it has been reported from sheep (Naem and Gorgani, 2011) and goats also. Mayo et al. (2013) described goat and sheep infection of this nematode from Iberian Peninsula and Spain respectively. Mao et al. (2013) explained Camelostrongylus presence in sheep based on phylogenetic and specific relationship between parasite and its ancient host.

\section{Gongylonema pulchrum}

It is also known as tailor worm of oesophagus. G. pulchrum is parasite common in cattle. However, it has been reported in sheep as well as in goats from Iraq (Naem and Gorgani, 2011; Al- Bayati et al., 2009), Algeria (Papini et al., 2013). In Algeria $15 \%$ of goats and $5.5 \%$ of sheep examined were found positive for Gongylonemiasis (Papini et al., 2013). Papini et al. (2013) also discussed the zoonotic aspect of Gongylonema infection.

\section{Strongyloides spp.}

The Strongyloidosis is common infection in small ruminants. It has been reported worldwide i.e. Korea (Gebeyehu et al., 2013) Pakistan (Farooq et al., 2012) Thailand (Sangvaranond et al., 2010; Worasing et al., 2011), Sudan (Almalaik et al., 2008), India (Sutar et al., 2010; Lone et al., 2012; Singh et al., 2013; Khajuria et al., 2013; Varadharajan and Vijayalakshmi, 2015; Brahma et al., 2015), Bangladesh (Rahman et al., 2014; Hossain et al., 2015), Malaysia( Tan et al., 2017) Nigeria (Okoye et al., 2013; Owhoeli et al., 2014), Ethiopia (Ibrahim et al., 2014), Ghana (Blackie 2014; Futagbi et al., 2015), Zimbabwe (Zvinorova et al., 2016)

The prevalence of Strongyloides spp. has been reported as high as 13.3 to 84.6 percent in goats in Nigeria (Okoye et al., 2013; Owhoeli et al., 2013), 23.5 percent in Korea (Gebeyehu et al., 2013), 16.3-25.9 percent in Ethiopia (Ibrahim et al., 2014), 3.55 percent in Egypt( Hassan et al., 2019)up to 100 percent in Ghana (Futagbi et al., 2015), 3.22-6.00 percent in Pakistan (Farooq et al., 2012), 26.5 percent in Sudan (Almalaik et al., 2008), 100 percent in Ghana (Futagbi 2015), 3.75-47 percent India (Sutar et al., 2010; Lone et al., 2012; Brahma et al., 2015), 6-29 percent in Nepal ( Karki et al., 2012), 5.0-11.11 percent in Bangladesh (Rahman et al., 2014; Hossain et al., 2015), 7.26 percent in Thailand (Sangvaranond et al., 2010).

Prevalence reported in sheep was 26.2 percent in Sudan (Almalaik et al., 2008), 13.04-20.10 percent in Ethiopia (Ibrahim et al., 2014). Almalaik et al. (2008) reported damage in intestinal mucosa in most of the infected sheep and goats by Strongyloides spp.

\section{Trichuris spp.}

The occurrence of Trichuris spp. in small ruminants has been reported from Bangladesh (Nath et al., 2011; Hossain et al., 2015), Sri Lanka ( Kandasami et al. 2013), 
Pakistan (Farooq et al., 2012; Raza et al., 2014 ), Thailand (Worasing et al., 2011), Sudan (Almalaik et al., 2008), Korea (Gebeyehu et al., 2013), India (Sutar et al., 2010), Iran ( Radfar et al., 2011), Ghana (Blackie, 2014; Futagbi et al., 2015), Zimbabwe ( Zvinorova et al., 2016), Ethiopia (Sissay et al., 2007; Dagnachew et al., 2011), Egypt (Khalafalla et al., 2011),

Prevalence of Trichuris spp. infection described by various worker varied in range of 0.6- 68.6 in goats (Almalaik et al., 2008; Kenyari et al., 2009; Sutar et al., 2010; Radfar et al., 2011; Nath et al., 2011; Gebeyehu, et al., 2013; Hossain et al., 2015; Futagbi et al., 2015; Zvinorova et al., 2016, Hassan et al., 2019) and ranged 0.1-47.8 percent in Sheep (Almalaik et al., 2008; Dagnachew et al., 2011; Kandasamy et. al., 2013; Farooq et al., 2012; Sultan et al., 2016). Nath et al. (2011) from Bangladesh, however, reported higher prevalence rate in winter than in rainy season. Dagnachew et al. (2011) reported Trichuris prevalence significantly more in young animals compared to adults both in sheep and goats as well. Variations in prevalence due to sex and age as reported by Radfar et al. (2011) were non-significant but they suggested a definite seasonal sequence in the nematode burden and faecal egg counts in goats corresponding with the pattern of rain.

There were two species, Trichuris globulosa and T. ovis reported to infect goats and sheep (Sissay et al., 2007; Almalaik et al., 2008).

Nath et al. (2011) described the lesion caused by Trichuris spp. as catarrhal inflammation along with petechial haemorrhage on intestinal mucosa and proliferation of goblet cells.

\section{Capillaria spp.}

Infection of Capillaria spp. in goats was reported from Bangladesh (Rabbi et al., 2011), Thailand (Jittapalapong et al., 2012). However, the prevalence was scanty and as low as less than 2 percent.

\section{Graphidiops spp.}

Sultan et al. (2010) and Khalafalla et al. (2011) described Graphidiops spp. infection for the first time in sheep from Nile Delta, Egypt. Khalafalla et al. (2011) reported 2.9 percent abomasal prevalence of this nematode from slaughter sheep.

\section{Parabronema skrjabini}

The parasite is known to occur in abomasums of ruminants and characterized by the presence of large cuticular shields and cordons in cephalic region. Khalafalla et al. (2011) reported P. skrjabini infection in slaughtered sheep in Egypt and described that 2.9 percent of abomasums in slaughtered sheep in Egypt were infected with nematode.

\section{Skrjabinema ovis}

Almalaik et al. (2008) reported prevalence of Skrjabinema ovis prevalence in sheep and goats as 0.3 and 11.6 percent respectively. Naem and Gorgani, (2011) reported Skrjabinema ovis in sheep from Iran with a prevalence of 4 percent. Papini et al. (2013) reported the Skrjabinema sp. from South West Algeria in sheep and goats.

\section{Gaps in Nematodes Research}

Among nematodes, strongyle worms including hookworm infections were among most frequently reported nematode infections during review period. Stomach worms Haemonchus and Trichostrongylus spp. were most rampant and challenging pathogens in the region but Ostertagia (Telodorsagia), Nimatodirus spp. infection, specially in African continent, was not exception. Marshallagia spp. infection was observed distinctly distributed in some oriental and Middle East countries. Worms like Trichuris, Chabertia and Oesophagostomum spp. in caecum and colon and Strongyloides spp. in intestine were most reported and discussed. Besides these common and widely distributed nematodes some scarcely localized infections like Camelostrongylus, Graphidiops, Parabronema and Skrjabinema spp. have also been reported. However, their pathogenic potential or severity of infection remained undiscussed. Similarly, nematode like Cooperia, Nimatodirus also could not get their due attention. This can be attributed to their minimal economic value, scarce presence in specific geographical region and low intensity of infection. But as they are present as concurrent infection with other known pathogenic nematode parasites, the gravity of their infection could have been masked and overlooked in the shadow of serious pathogen. It is emphasized that pathogenic aspect of these lesser known nematodes should be explored with host-parasite interaction study. There is considerable scope to work and improve the forecasting and 
also the measurements of helminthes response to climate change. Modern molecular methods, both quantitative and qualitative, have not still been adapted for rapid estimation of level of parasitic challenges as they can be helpful to fight against worms. The work on female worm fecundity would help to overcome the frequent infection by improving the pasture conditions. Further there is need to study them for immunological reaction invoked by them if any, to find out a common candidate potential antigen. Molecular epidemiology of these nematodes may further help to establish their phylogenic relationship if any in the course of evolution.

The strongyle worms and other nematode parasites of small ruminants are indeed a huge economic problem affecting the livestock productivity. Despite the use of anthelmintics, there lies a dangerous anthelmintics resistance (AR) development (Kaushik et al., 2016) that haywires the effectiveness of parasite control strategies. The need of the hour is to overcome the AR by identifying the markers in the parasites that differentiates the sensitive and resistance worm population. This can be an excellent domain to work on. Similarly interference in female worm fecundity could contribute to helminthic control. In hypobiosis, factors governing inhibition length and time of emergence of arrested larvae are still undisclosed or poorly understood specially biochemical intricacy involved. Over-the-top molecular techniques like NGS based transcriptomics or metagenomics can zero-in to the parasite-linked marker gene affecting the host susceptibility and (HS as well as contributing to AR. It can also be useful in unraveling the mechanism behind emergence of arrested larvae. If we can address the twin problems of HS and AR, then there is a huge possibility to contain the nematode menace.

\section{CONCLUSION}

Gastrointestinal helminthic infections in sheep and goats remained serious threats for their production as seen by various study conducted in last decade also. Though some infections like fasciolosis, amphisotomosis, haemonchosis, trichostrongylosis, oesophagostomosis were well known, quite discussed and studied in past, the other disease like cestodosis, schistosomosis and trichuriosis, gongylonemiasis could not get due attention either due to their low pathogenicity or more of zoonotic value. Further, infection like Graphidiops, Skrjebinema,
Camelostrongylus and Parabronema in sheep and goats still remained almost as puzzle as nothing sort of their life cycle, economic importance and pathogenicity could get attention. Authors feels that these lesser known parasites need to be studied in the light of concurrent infection and their phylogenetic relationship with other similar parasites including the host-parasite relationship. Various molecular tools available these days can help to unravel the undisclosed part of epidemiology of these infections which may be helpful to control these infections.

\section{Funding}

Being it review article, it did not receive any specific grant from funding agencies in the public, commercial, or notfor-profit sectors.

\section{Declaration of conflict of interest}

No conflict of interest with respect to the publication of the manuscript lies among the scientists.

\section{Acknowledgements}

Authors duly recognize the support and technical help extended by Director, Central Institute for Research on Goats, Makhdoom, Mathura (India).

\section{REFERENCES}

Abdel-Megeed Kadria, N., Hassan Soad, E., Abu El-Ezz Nadia, M.T. and Farag Tarek, K. 2014 Diagnosis of Monieziasis Using Adult Moniezia expansa Affinity Partially Purified Antigen. Glob. Vet., 13(5): 814-819

Agrawal, M.C. 2012 Schistosomes and Schistosomiasis in South Asia. Springer Science \& Business Media, ISBN 978-81322-0539-5, pp. 352

Agrawal, N., Sharma, D.K. and Mandal, A. 2010. Faecal egg output in Jakhrana goats naturally infected by Haemonchus contortus, Physiological states and seasons effect. Indian $J$. Anim. Sci., 80(5): 509-511.

Akca, A., Gokce, H. I. and Mor, N. 2014. Seroprevalence of Fasciola hepatica infection in cattle and sheep in the province of Kars, Turkey, as determined by ELISA. Helminthologia, 51(2): 94-97.

Al-Bayati, O.A.S. and Arsalan, S.H. 2009. Clinical and hematological study in sheep infected with gastrointestinal parasites in Mosul. Iraqi J. Vet. Sci., 23: 93-100. 
Ali, T.S., Zarichehr, V., Reza, T.M., Amroallah, B., Hossin, T., Amir, M., Akbar, T., Hossin H., Tourag, R.T. and Hassan, E. 2011. Prevalence of liver flukes infections in slaughtered animals in Kashan, Isfahan Province, Central Iran. The IIOAB J., 2(5): 14-18

Almalaik, A.H.A., Bashar, A.E. and Abakar, A. 2008. Prevalence and Dynamics of some gastrointestinal parasites of sheep and goats in Tulus area based on post- mortem examination. Asian J. Anim. Vet. Adv., 3(6): 390-399.

Amadi, A.N.C., Avoaja, D.A. and Essien, E.J. 2012. Epidemiology of Helminth Parasites of West African Dwarf Goat (Capra hircus) in Umuariaga in Ikwuano LGA, Abia State. J. Appl. Sci. Environ. Manage., 16(4): 359-362.

Aragaw Kassaye and Gebreegziabher Gebrehiwot 2014. Small Intestinal Helminth Parasites in Slaughtered Sheep and Goats in Hawassa, Southern Ethiopia. Afri. J. Basic Appl. Sci., 6(2): 25-29.

Arbabi, M., Nezami, E., Hooshyar, H. and Delavari, M. 2018. Epidemiology and economic losses of fasciolosis and dicrocoeliosis in Arak, Iran. Vet. World, 11(12): 1648-1655.

Asrani, R.K., Mittra, S., Kishtwaria, R.S., Agnihotri, R.K., Gupta, V.K. and Sharma, M. 2011. Outbreak of mixed parasitic infection in a migratory flock of Gaddi sheep and goats. Haryana Vet., 50: 92-94.

Attindehou, S. and Salifou, S. 2012 Epidemiology of Cestodes Infections in sheep and goats in Benin. Vet. Res., 5(3): 59-62.

Babar, M.E., Hussain, T., Ahmad, M.S., Ali, A., Kamran, A. and Ali, M.M. 2015. Evaluation of Pakistani goat breeds for genetic resistance to Haemonchus contortus. Acta Vet. Brno., 84: 231-235.

Badaso, T. and Addis, M. 2015. Small Ruminant Haemonchosis Prevalence and Associated risk factors in Arsi Negelle Municipal Abattoir, Ethiopia. Glob. Vet., 15(3): 315-320.

Bandhyopadhyay, S., Devi P., Bera, A., Bandhyopadhyay, S. and Bhattacharya, D. 2010. Prevalence of Gastrointestinal Parasites in Goats in Shillong Meghalaya, India. Webmed Central Parasitology, 1(9): WMC00777.

Bashtar, A.R., Hassancin, M., Abdel-Ghaffar, F., Al-Rasheid, K., Hassam, S., Mchlhorn, H., Al-Mahdi, M., Morsy, K. and Al-Ghamdi, A. 2011. Studies on Monieziosis of sheep I. Prevalence and anthelmintics effects of some plant extracts, a light and electron microscopic study. Parasitol. Res., 108: 177-186.

Bihaqi, S.J., Allaie, I.M., Banday, M.A.A., Wani, Z.A., and Shahardar, R.A. 2017. Prevalence of caprine GI helminths in temperate areas of Jammu \& Kashmir. J. Parasit. Dis., 41(3): 843-849.

Blackie, Seth. 2014. A Review of the Epidemiology of Gastrointestinal Nematode Infections in sheep and goats in Ghana. J. Agri. Sci., 6(4): 109-118
Brahma, A., Pandit, S., Kumar, D., Ghosh, J. and Jas, R. 2015. Prevalence of Gastrointestinal Helminthosis in Black Bengal Goats of Organized farm in West Bengal. Indian J. Anim. Hlth., 54(1): 27-34.

Bulbul, K.H., Baruah, N., Saleque, A. and Das, M. 2014. Epidemiological studies on fasciolosis at organized goat (Capra hircus) farm of Assam. J. Vet. Parasitol., 28(2): 132136.

Chang Qiao-Cheng, Liu Guo-Hua, Gao Jun-Feng, Zheng Xu, Zhang Yan, Duan Hong, Yue Dong-Mei, Xue Fu, Xin $\mathrm{Su}$, Yuan Gao and Wang Chun-Ren 2016. Sequencing and characterization of the complete mitochondrial genome from the pancreatic fluke Eurytrema pancreaticum (Trematoda: Dicrocoeliidae). Gene, 576(1): 160-165.

Chiejina, S.N., Behnke, J.M. and Fakae, B.B. 2015. Haemonchotolerance in West African Dwarf goats: contribution to sustainable, anthelmintics-free helminth control in traditionally managed Nigerian dwarf goats. Parasite, 22: 7.

Choubisa, S.L. 2010. Snails as bio-indicator for dreaded trematodiasis diseases. J. Commun. Dis., 42(3): 223-226.

Dagnachew, Shimelis, Amamute, Asmare and Temesgen Wuda 2011. Epidemiology of gastrointestinal helminthiasis of small ruminants in selected sites of North Gondar zone, Northern Ethiopia. Ethiop. Vet. J., 15(2): 57-68.

Elkhtam, A.O. and Khalafalla, R.E. 2016. Surveillance of Helminthes and Molecular phylogeny of Fasciola gigantica infecting goats in Sadat District, Egypt. IJ SR S T, 2(4): 188192.

Ezatpour, B., Hasanvand, A., Azami, M., Anbari, K. and Ahmadpour, F. 2015. Prevalence of liver fluke infections in slaughtered animals in Lorestan, Iran. J. Parasit. Dis., 39(4): 725-729.

Farooq, Z., Mushtaq, S., Iqbal, Z. and Akhtar, S. 2012. Parasitic helminths of domesticated and wild ruminants in Cholistan desert of Pakistan. Int. J. Agric. Biol., 14(1): 63-68.

Futagbi, G., Abankwa, J.K., Agbale, P.S. and Aboagye, I.F. 2015. Assessment of Helminth Infections in Goats Slaughtered in an Abattoir in a suburb of Accra, Ghana. West Afri. J. Appl. Ecol., 23(2): 35-42.

Gebeyehu, E.B., Seo, M.G., Jung, B.Y., Byyb, J.W., Oem, J.K., Kim, H.Y. and Kwak, D. 2013. Prevalence of Gastrointestinal Parasites in Korean Native Goats (Capra hircus aegagrus). J. Anim. Plant Sci., 23(4): 96-989.

Gizachew, A., Fikadu, N. and Birhanu, T. 2014. Prevalence and associated risk factors of major sheep gastrointestinal parasites in and around Bako Town, Western Ethiopia. Livestock Res. Rural Dev., 26(10) 
Godara, R., Katoch, R., Yadav, A. and Borah, M.K. 2014. Dicrocoeliosis in goats in Jammu. Indian J. Parasit. Dis., 38(2): 201-204.

Hassan, N.M.F., Farag, T.K., Abu El Ezz, N.M.T., Abou-Zeina, H.A.A. 2019. Prevalence assessment of gastrointestinal parasitic infections among goats in Giza Governorate, Egypt. Bull. Natl. Res. Cent., 43: 127.

Hossain, M., Bhuiyan, M.J., Alam, M.S., Islam, K.M., Nath, T.C., Dutta, R. and Musleh Uddin, A.H.M. 2015. Cross sectional epidemiological investigation on the prevalence of gastrointestinal parasites of small ruminants in Sullah Upazilla of Sunamgonj District, Bangladesh. J. $A d v$. Parasitol., 2(4): 100-104.

Ibrahim, Nuraddis, Tefera, Mulugeta, Bekele, Mihreteab and Alemu, Sisay 2014. Prevalence of Gastrointestinal parasites of small ruminants in and around Jimma Town, Western Ethiopia. Acta Parasitologica Globalis, 5(1): 26-32.

Islam, K.M., Islam, M.S., Rauf, S.M.A., Khan, A., Adhikary, G.N. and Rahman, M. 2016. Patho-Surveillance and Pathology of Fasciolosis (Fasciola gigantica) in Black Bengal Goats in Bangladesh. J. Ani. Sci. Adv., 6(12): 1837-1845.

Jas, R., Ghosh, J.D., Pandit, S. and Das, K. 2010. Haematobiochemical impact of primary infection of Oesophagostomum columbianum in goat. J. Vet. Parasitol., 24(2): 117-120.

Jittapalapong, S., Saengow, S., Pinyopanuwat, N., Chimnoi, W., Khachaeram, W. and Stich, R.W. 2012. Gastrointestinal Helminthic and Protozoan infections of goats in Satun, Thailand. J. Trop. Med. Parasitol., 35(2): 48-54.

Kandasamy, G., Rajapakse, R.P.V.J. and Rajakaruna, R.S. 2013. Gastrointestinal and blood parasites of a free grazing flock of sheep in Kaithady farm in Jaffna District. J. Nat. Sci. Foundation Sri Lanka, 41(3): 195-201.

Karki Kedar, Bashir Bimla Kumari and Subedi Janak Raj. 2012. A case study on seasonal prevalence of Helminth parasites in Goats (Capra hircus) in Kananki (Khasibazzar), Kathmandu Nepal. Bulletin of Environment, Pharmacology and Life Sciences, 1(2): 11-13.

Kaushik, R., Rout, P.K. and Sharma, D.K., Souvik, Paul. 2016. Molecular characterization of $\beta$-tubulin isotype -1 gene of Haemonchus contortus in goats with focus on Benzimidazole resistance. Animal Science Reporter, 10(2): 48-54

Kerie, Y. and Seyoum, Z. 2016. Bovine and ovine schistosomiasis: Prevalence and associated host factors in selected sites of South Achefer district, northwest Ethiopia. Thai. J. Vet. Med., 46(4): 561-567.

Khajuria, J.K., Katoch, R., Yadav, Anish, Godara, R., Gupta, S.K. and Singh, Ajitpal. 2013. Seasonal prevalence of gastrointestinal helminthes in sheep and goats of middle agro-climatic zone of Jammu province. J. Parasit. Dis., 37(1): $21-25$
Khalafalla, R.E., Elseify, M.A. and Elbahy, N.M. 2011. Seasonal prevalence of gastrointestinal nematode parasites of sheep in Northern region of Nile Delta, Egypt. Parasitol. Res., 108: 337-340.

Khan, M.N., Sajid, M.S., Khan, M.K., Iqbal, Z. and Hussain, A. 2010. Gastrointestinal helminthiasis, prevalence and associated determinants in domestic ruminants of district Toba Tek Singh, Punjab, Pakistan. Parasitol. Res., 107(4): 787-794.

Khan, S.A., Muhammad, S., Khan, M.M. and Khan, M.T. 2015. Study on the Prevalence and Gross Pathology of Liver fluke infestation in sheep in and around Quetta District, Pakistan. Adv. Anim. Vet. Sci., 3(3): 151-155.

Khanjari Ali, Bahonar Alireza, Fallah Sepideh, Bagheri Mahboube, Alizadeh Abbas, Fallah Marjan and Khanjari Zahra. 2014. Prevalence of Fasciolosis and dicrocoeliosis in slaughtered sheep and goats in Amol Abattoir, Mazandaran, northern Iran. Asian Pac. J. Trop. Dis., 4(2): 120-124.

Khoramian Hassan, Arbabi Mohsen, Osqoi Mahmood Mahami, Delavari Mahdi, Hooshyar Hossein and Asgari Mohammarreza 2014. Prevalence of ruminant fascioliasis and their economic effects in Kashan, center of Iran. Asian Pac. J. Trop. Biomed., 4(11): 918-922.

Kumar Deepesh, Vatsa Stuti and Kumar Rajeev Ranjan 2013. Preparation of bioclimatograph for strongylosis in small ruminants of Tarai region of Uttrakhand. J. Vet. Parasitol., 27(2): 3-87.

Kumsa, B., Tadesse, T., Sori, T., Duguma, R., Hussen, B. 2011. Helminthes of sheep and goats in Central Oromia (Ethiopia) during the dry season. J. Anim. Vet. Adv., 10: 1845-1849.

Lone, B.A., Chisti, M.Z., Ahmad, F. and Tak, H. 2012. A survey of Gastrointestinal Helminth Parasites Slaughtered Sheep and Goats in Ganderbal, Kashmir. Glob. Vet., 8(4): 338-341.

Maitra, A., Yadav, C.L. and Sanjukta, R.K. 2014. Seasonal prevalence of paramphistomosis in domestic ruminants in different agro-climatic zones of Uttarakhand, India. Asian Pac. J. Trop. Dis., 4 (Suppl. 2): S748-S753.

Mandal, A., Agarwal, N., Nigam, Puja, Sharma, D.K. and Roy, R. 2011. Susceptibility of Haemonchus contortus infection in Jakhrana goats. Indian J. Anim. Sci., 81(2): 149-151.

Melaku, S. and Addis, M. 2012. Prevalence and intensity of Paramphistomum in ruminants slaughtered at Debre Zeit industrial abattoir, Ethiopia. Glob. Vet., 8(3): 315-319.

Meradi, S., Bentounsi, B., Zouyed, I. and Cabaret, J. 2011. The steppe species of gastrointestinal nematodes of small ruminants, with a focus on Marshallagia: Climate as a key determinant. Parasite, 18: 261-269.

Mhoma, J.R.L., Kanyari, P.W.N. and Kagira, J.M. 2011. The prevalence of gastrointestinal parasites in goats in urban and 
peri urban areas of Mwanza City, Tanzania. Sci. Parasitol., 12(4): 191-196.

Moradpour, N., Borji, H., Razmi, G., Kazemi, H. and Maleki, M. 2014. Comparison of two methods of Marshallagia marshalli donor sheep production. J. Parasit. Dis., 38(3): 289-292.

Moradpour, N., Borji, H., Razmi, G., Maleki, M. and Kazemi, H. 2013. Pathophysiology of Marshallagia marshalli in experimentally infected lambs. Parasitology, 140(14): 17627.

Musotsi, P.Y., Otieno, C.A. and Njoroge, S. 2017. Prevalence of Fasciolosis in Cattle, Sheep and Goats slaughtered in slaughter slabs in Trans-Nzoia West, Kenya and knowledge of livestock handlers. Journal of Biology, Agriculture and Healthcare, 7(6): 34.

Naem Soraya and Gorgani, Tahmineh 2013. Gastrointestinal parasitic infection of slaughtered sheep (Zel breed) in Fereidoonkenar city of Iran. Vet. Res. Forum, 2(4): 238-241.

Nagesh, D. and Das, V.V. 2015. Prevalence of Helminth Parasites in Sheep of Medak District, Telangana India. Int. J. Sci. Res., 5(5): 1946-1948.

Nasrullah, O.J., Slemane, R. and Abdullah, S. 2014. Prevalence of the gastrointestinal tract parasite in goats in Sulaiman Province. Assiut. Vet. Med. J., 60(141): 25-28.

Nath Babu Kanti, Roy Krishna, Shailkat Amir Hossan, Shil Subrata Kumar and Islam Md. Zohorul 2011. A study on Prevalence and Pathological effects of Intestinal Helminths in Black Bengal Goat in Chittgong. Vet Scan, 6(2): Article 99.

Ndom Mallé, Diop Gora, Quilichini Yann, Yanagida Tetsuya, Ba Cheikh Tidiane and Marchand Bernard 2016. Prevalence and Scanning Electron Microscopic Identification of Anoplocephalid cestodes among Small Ruminants in Senegal. J. Parasitol. Res., Article ID 3937292, 9 pages http://dx.doi. org/10.1155/2016/3937292

Ntonifor, H.N., Shei, S.J., Ndaleh, N.W. and Mbunkur, G.N. 2013. Epidemiological studies of gastrointestinal parasitic infections in ruminants in Jakiri, Bui Division and North West Region of Cameroon. J. Vet. Med. Anim. Hlth., 5(12): 344-352.

Odeniran, P.O., Jegede, H.O. and Adewoga, T.O.S. 2016. Prevalence and risk perception of adult-stage parasites in slaughtered food animals (cattle, sheep and goat) among local meat personnel in Ipata abattoir, Ilorin, Nigeria. Veterinary Medicine and Animal Sciences, doi 10.7243/2054-3425-4-1.

Okoye Ikem C., Obiezue Rose N., Okoye Doris N. and Awi Michael 2013. High Prevalence of Gastro-Intestinal Parasites in Indigenous goats of Nigeria. Paripex-Indian J. Res., 2(10): 17-20.

Owhoeli Ovutor, Elele Kingsley and Gboeloh Lebari Barine
2014. Prevalence of Gastrointestinal Helminths in Exotic and Indigenous Goats slaughtered in selected abattoirs in Port Harcourt, South-South Nigeria. Chin. J. Biol., Article ID 435913, 8 pages.

Ozdal, N., Gul, A., Ilhan, F. and Deger, S. 2010. Prevalence of Paramiphistomum infection in cattle and sheep in Van Province, Turkey. Helminthologia, 47(1): 20-24.

Papini, R., Cecchi, V., Capocchi, O., Mancianti, F. 2013. Small ruminant Gongylonema pulchrum infection in the South West Algerian desert: prevalence of a sporadic zoonosis. Med. Weter, 69(3): 161-164.

Qamar Muhammad Fiaz, Maqbool Azhar, Khan Muhammad Sarwar, Ahmad Nisar and Muneer Muhammad Akram. 2009. Epidemiology of Haemonchosis in sheep and Goats under different managemental conditions. Vet. World, 2(11): 413417.

Rabbi, A., Islam, A., Anisuzzaman, A., Majumdar, S. and Rahman, Mh. 2011. Does feeding system influence parasitism in black Bengal goats in Bangladesh. Progress. Agric., 22(1\&2): 85-95.

Radfar, M.H., Sakhaee, E., Bafti Shamsaddini, M. and Gah Nigannadu, G. 2011. Study on gastrointestinal parasitic infections of Raeinei goats. Iranian J. Vet. Res. Shiraz University, 12(1) S. No. 34: 76-80.

Rahman, M.A., Sharifuzzaman, Khokon J.U., Saker, E.H., Shahiduzzaman, M. and Musofa, M. 2014. Prevalence of parasitic diseases of goat at Pirganj Upjila of Bangladesh. Int. J. Nat. Soc. Sci., 1: 8-12.

Raza, M.A., Younas, M. and Schlecht, E. 2014. Prevalence of Gastrointestinal helminthes in pastoral sheep and goat flocks in Cholistan desert of Pakistan. J. Anim. Plant Sci., 24(1): 127-134.

Rojo-Vázquez, F., Meana, A., Valcárcel, F. and MartínezValladares, M. 2012. Update on trematodes infections in sheep. Vet. Parasitol., 189(1):15-38.

Saifullah, M.K., Ahmad, G., Nizami, W.A. and Abidi, S.M.A. 2011. Isolation and partial characterization of excretory/secretory antigens Gastrothylax crumenifer. Vet. Parasitol., 180(3-4): 232-236.

Samaila, M.O., Shehu, S.M., Abubakar, N., Mohammed, U. and Jabo, B. 2009. Human dicrocoeliasis presenting as a subcutaneous mass. BMJ Case Reports, doi: 10.1136/ bcr.02.2009. 1622 .

Sangma, A., Begum, N., Roy, B.C. and Gani, M.O. 2012. Prevalence of helminth parasites in sheep (Ovis aries) in Tangail district, Bangladesh. J. Bangladesh Agril. Univ., 10(2): 235-244.

Sangvaranond Arkom, Lampa Natipong, Wongdachkajorn Dachpathon and Sritong Devirat 2010. Prevalence of 
Helminth Parasites and Intestinal Parasitic Protozoa among Meat Goats raised in Private Farms in Saraburi Province Thialand. Kasetsart Veterinarians, 20(2) : 85-93.

Sankar, M., Bhatt, M., Gowane, G.R., Narayanan, K., Kumar, M., Zahid, A.K., Saravanan, B.C., Allie, I., Subramani, V., Sharma, A.K. and Prasad, A. 2016. Effect of non-genetic factors on the prevalence of Stilesia globipunctata in the goat. Helminthologia, 53(2): 186-190.

Schwertz, C.I., Lucca, N.J., Silva, A.S., Baska, P., Bonetto, G., Gabriel, M.E., Centofanti, F. and Mendes, R.E. 2015. Eurytrematosis, An emerging and neglected disease in South Brazil. World J. Exp. Med., 5(3): 160-33.

Shaikh, K., Manoronjano, N. and Bhure, D. 2011. Seasonal variation of Moniezia in Capra hircus from Aurangabad district (M.S), India. Biosci. Discovery, 2: 199-200.

Sharma, D.K., Agrawal, Nimisha, Mandal Ajoy, Nigam Puja and Bushan Saket 2009. Coccidia and Gastrointestinal Nematode infections in semi-intensively managed Jakhrana goats of semi-arid region of India. Trop. Subtrop. Agroecosyst., 11: 135-139.

Sharma, S., Busang, M. 2013. Prevalence of some gastrointestinal parasites or ruminants in Southern Botswana. Bots. J. Agric. Appl. Sci., 9(2) : 97-103.

Siddiqua, B. 2010. Incidence of common Helminth Parasites in Goats and Sheep in Ghatampur Area of Kanpur Dehat. Trends in Biosciences, 3(1): 66-67.

Siddiqua, B. and Prakash, V. 2009. Pathology of naturally occurring Fasciolosis in goats. Trends in Biosciences, 2(1): 16-17.

Singh, Alok Kumar, Das, G., Roy, B. and Nath, S. 2015. Prevalence of gastro-intestinal parasitic infections in goat of Madhya Pradesh, India. J. Parasit. Dis., 39(4): 716-719.

Singh, V., Varshney, P., Dash, S.K. and Lal, H.P. 2013. Prevalence of gastrointestinal parasites in sheep and goats in and around Mathura, India. Vet. World, 6(5): 260-262.

Sissay, M.M., Uggala, A. and Waller, P.J. 2007. Prevalence and seasonal incidence of nematode parasites and fluke infections of sheep and goats in eastern Ethiopia. Trop. Anim. Health Prod., 39: 521-531.

Sissay, M.M., Uggla, A. and Waller, P.J. 2007. Epidemiology and seasonal dynamics of gastrointestinal nematode infections of sheep in a semi-arid region of eastern Ethiopia. Vet. Parasitol., 143(3-4) : 311-321.

Sissay, M.M., Uggla, A. and Waller, P.J. 2008. Prevalence and seasonal incidence of larval and adult cestodes infections of sheep and goats in Ethiopia. Trop. Anim. Health Prod., 40(6): 387-94.

Soloman-Wisdom, G.O., Matur, B.M. and Ibe, K.C. 2014. Prevalence of intestinal Helminth infection among sheep and goats raised for slaughtering in Gwagwalada abattoir, AbujaNigeria. J. Global Pharmaceutical Sci., 2(1): 12-19.

Sultan, K., Desoukey, A.Y., Elsiefy, M.A. and Elbahy, N.M. 2010. An abattoir study on the Prevalence of some gastrointestinal helminthes of sheep in Gharbia Governorate, Egypt. Glob. Vet., 5(2): 84-87.

Sultan Khaled, Elmonir Walid and Hegazy Yamen 2016. Gastrointestinal parasites of sheep in Kafrelsheikh governorate, Egypt, Prevalence, control and public health implications. Beni- Suef Univ. J. Basic Appl. Sci., 5: 79-84.

Sutar, A.U., Kengar, S.B., Patil, S.S. and Khan, M.R. 2010. Prevalence of gastrointestinal parasites in goats of Ahmadnagar district of Maharashtra. Vet. World, 3(10): 456457.

Swarnkar, C.P. and Singh, D. 2012. Epidemiology of gastrointestinal helminths in stationary and migratory sheep flocks in arid Rajasthan. J. Vet. Parasitol., 26: 112-117.

Swarnkar C.P., Khan F.A. and Singh D. 2019. Prevalence of fluke infestation in sheep flocks of Rajasthan, India. Biol. Rhythm Res., DOI: 10.1080/ 09291016. 2019. 1600262.

Talukder, S., Bhuiyan, M.J., Hossain, M.M., Uddin, M.M., Paul, S. and Howlader, M.M.R. 2010. Pathological investigation of liver fluke infection of slaughtered Black Bengal goat in selected area of Bangladesh. Bangl. J. Vet. Med., 8(1): 35-40.

Tan, T.K., Chandrawathani, P., Low, V.L., Premaalatha, B., Lee, S.C., Chua, L.H., Sharma, R.S.K., Romano, N., Tay, T., Quaza, N.H.N. and Lim, Y.A.L. 2017. Occurrence of gastrointestinal parasites among small ruminants in Malaysia, highlighting Dicrocoelium infection in goats. Trop. Biomed., 34(4): $963-969$

Taylor, M.A. 2012. Emerging parasitic diseases of sheep. Vet. Parsitol., 189(1): 2-7.

Tehrani, A., Javanbakhat, J., Khani, F., Hassan, M.A., Khadivar, F., Dadasi, F., Alimohammadi, S. and Amani, A. 2015. Prevalence and pathological study of Paramphistomum infection in the small intestine of slaughtered ovine. $J$. Parasit. Dis., 39(1): 100-106.

Tramboo, S.R., Shahardar, R.A., Allaie, I.M., Wani, Z.A. and Bushra, M.S. 2017. Prevalence of gastrointestinal helminth infections in ovine population of Kashmir Valley. Vet. World, 8(10): 1199-204.

Usman, A.M., Babeker, E.A. and Malann, Y.D. 2016. Prevalence of Gastrointestinal parasitic infections among ruminants animals slaughtered in Katagum abattoir of Bauchi state, Nigeria. Int. J. Innov. Res. Adv. Stud., 3(12) : 167-170.

Varadharajan, A. and Vijayalakshmi, R. 2015. Prevalence and seasonal occurrence of gastrointestinal parasites in small ruminants of coastal areas of Tamil Nadu. Int. J. Scient. Res. Public., 5(2): 1-6. 
Verma, R., Sharma, D.K., Paul, S., Gururaj, K., Dige, M., Saxena, V.K., Rout, P.K., Bhusan, S. and Banerjee, P.S. 2018. Common Gastrointestinal Parasitic Infections in Goats reared in Semi- Arid Region of India. J. Anim. Res., 8(1): 39-45.

WHO 2007. WHO initiative to estimate the global burden of food borne diseases. Proceedings of the $1^{\text {st }}$ Formal Meeting of the Food Borne Disease Burden Epidemiology Reference Group, November 26-28, World Health Organization, Geneva, Switzerland.

WHO (World Health Organization) 2006. Animal Production and health paper No. 78, USA
Worasing, R., Chaisalee, P. and Wondee, M. 2011. The status of gastrointestinal parasites in goats in southern Thailand. Proceedings of $49^{\text {th }}$ Kasetsart University Annual Conference, Kasetsart Thailand, 2: 141-150.

Yadav, C.L., Rajeev, R.K., Stuti, V. and Rajat, G. 2010. Prevalence of amphistomosis in ruminants in national capital region, Delhi. J. Vet. Parasitol., 24: 125-127.

Zvinorova, P.I., Halimani, T.E., Muchadeyi, F.C., Matika, O., Riggio, V. and Dzama, K. 2016. Prevalence and risk factors of gastrointestinal parasitic infections in goats in low-input farming systems in Zimbabwe. Small Rumin. Res., 143: 7583. 